\title{
Selman A.Waksman zum 80. Geburtstag
}

Am 22. Juli begeht S. A. Waksman, Professor emerit. und Di-rektor emerit. des mikrobiologischen Instituts der Rutgers Univer-sität in New Brunswick, N.Y., seinen 80.

Geburtstag. In Priluka bei Kiew geboren, erhielt er 1910 als externer Gymnasiast in Odessa sein Immatrikulationsdiplom, mit dem er in die USA auswanderte. Im Herbst 1911 trat er ins Rutgers College ein, wo er an dessen Universität mit kurzfristigen Unterbrüchen verblieb.

Den Hinweis auf diesen Festtag verdanke ich Professor W. J. Nickerson, der als langjähriger Kollege von Waksman der Mei-nung war, daß ihm ein Geburtstagsgruß mehr Freude bereiten würde als die einmal kommenden Nachrufe.

Ich bin nicht kompetent, die Verdienste Waksmaris auf den Gebieten der Bodenbakteriologie, der Humusbildung, der Bedeu-tung der Mikroorganismen für marine Vorgänge, der Bildung und Natur antibiotischer Substanzen, der Taxonomie, Physiologie und Biochemie der Aktinomyceten kritisch zu würdigen, und vermag nicht einmal die von ihm und seinen Schülern geschaffenen Anti-biotika: Actinomycin (1940), Streptothricin (1942), Streptomycin (1943), Grisein (1946), Neomycin (1948) usw. objektiv zu werten. Hütter hat 1967 das in seiner in der «Bibliotheca Microbiologica» erschienenen Monographie «Systematik der Streptomyceten unter besonderer Berücksichtigung der von ihnen gebildeten Antibiotika» vollumfänglich getan. Ich bin im übrigen überzeugt, daß die Eh-rungen, die Herrn Waksman anläßlich seines Festtages zuteil werden, nicht nur durch Naturwissenschafter der verschiedensten Sparten erfolgen, sondern daß auch Kliniker die Gelegenheit be-nützen werden, ihm zu danken für das, was er für sie und ihre Patienten getan. Das erleichterte mir den Entschluß, den Jubilar heute daran zu erinnern, daß er nicht immer der Gebende war!

Herr Waksman beehrte mich 1947 auf der Rückreise vom 4. In-ternationalen MikrobiologenKongreß in Kopenhagen mit seinem Besuch. Im Verlaufe unseres Gesprächs erwähnte ich beiläufig den Streptomycin-Einsatz auf der Tuberkulose-Abteilung unserer Uni-

Selman A. Waksman zum 80. Geburtstag

59

versitätsklinik. Er war sichtlich erstaunt zu hören, daß das Prä-parat in Zurich schon im klinischen Versuch stand, und fragte mich, ob ich ihm wohl einen Besuch der Abteilung ermöglichen könnte, nicht etwa weil er mir nicht glaube, sondern weil er in seinem Leben noch nie einen «Tuberkulösen» gesehen hätte. Kol-lege Löffler, dem damaligen Direktor der Medizinischen Klinik, dem ich das Anliegen unterbreitete, machte es sichtlich Spaß, Herm Waksman zu empfangen. Er führte uns auf die Tuberku-lose-Abteilung, stellte den Patienten seinen Gast als den Schöpfer des Heilmittels, das sie erhielten, vor, was sie unter Klatschen zur Kenntnis nahmen.

Waksman war tief beeindruckt von dieser klinischen Visite. Er hatte sich Tuberkulöse ganz anders vorgestellt und war erstaunt, daß man eine solche Abteilung ohne Gesichtsmaske betreten und mit den Patienten sogar sprechen könnte.

Die Tatsache, daß der heutige Festtag die Erinnerung an dieses zwanzig Jahre zurückliegende Erlebnis auslöste, mag belegen, daß ich von der Reaktion des Naturwissenschafters Waksman 
nicht weniger beeindruckt war als er von seiner ersten Begegnung mit tuberkulösen Patienten. Frau Waksman möchte ich versichern, daß ich ihren an jenem Abend offengebliebenen Wunsch nach einem Alphornbläser heute wahrscheinlich zu erfüllen vermöchte.

A. Grumbach, Zurich. 